\title{
Novel Approaches for Concurrent Irradiation in Locally Advanced Cervical Cancer: Platinum Combinations, Non-Platinum-Containing Regimens, and Molecular Targeted Agents
}

\author{
Giannis Mountzios, ${ }^{1,2}$ Aspasia Soultati, ${ }^{1}$ Dimitrios Pectasides, ${ }^{3}$ \\ Meletios A. Dimopoulos, ${ }^{2}$ and Christos A. Papadimitriou ${ }^{2}$ \\ ${ }^{1}$ Department of Medical Oncology and Translational Research, 251 Air Force General Hospital, Neo Psychiko, 15451 Athens, Greece \\ ${ }^{2}$ Department of Clinical Therapeutics, University of Athens School of Medicine, "Alexandra" University Hospital, 11525 Athens, Greece \\ ${ }^{3}$ Second Department of Internal Medicine, University of Athens School of Medicine, "Hippocrateion" Hospital, 11525 Athens, Greece
}

Correspondence should be addressed to Giannis Mountzios; gmountzios@gmail.com

Received 24 February 2013; Revised 31 March 2013; Accepted 12 April 2013

Academic Editor: Robert Coleman

Copyright (C) 2013 Giannis Mountzios et al. This is an open access article distributed under the Creative Commons Attribution License, which permits unrestricted use, distribution, and reproduction in any medium, provided the original work is properly cited.

\begin{abstract}
Despite the available prevention and early detection strategies, squamous-cell carcinoma of the uterine cervix is still diagnosed as locally advanced disease in a considerable proportion of patients. As a potent sensitizer of cancer cells, cisplatin has been the "traditional partner" of external beam irradiation in this setting for more than two decades. Induction chemotherapy strategies followed by concurrent chemoradiation or surgery and preoperative concurrent chemoradiation have been recently implemented in clinical trials in an effort to optimize local control and to minimize the risk of distant metastases. In this context, cisplatin has been combined with a number of other potential radiosensitizers, including 5-fluorouracil, capecitabine, and gemcitabine. In patients resistant or intolerant to platinum compounds, numerous non-platinum-containing regimens have been developed, implementing various antimetabolites, taxanes, antineoplastic antibiotics, and topoisomerase II inhibitors. More recently, molecular agents targeting critical pathways in cervical malignant transformation are being assessed in early clinical trials in combination with external-beam irradiation. In the current work, we review the evolving role of cisplatin and other platinum compounds, either alone or in combination regimens, in the context of other potent radiosensitizers. The emerging role of molecular targeted agents, as candidate partners of external beam irradiation, is also discussed.
\end{abstract}

\section{Introduction}

Squamous carcinoma of the uterine cervix, often referred to as cervical cancer, remains a major concern for public health. Worldwide, cervical cancer accounted for 287,000 deaths in 2008 , and the number is expected to rise up to 410,000 by $2030[1,2]$. Despite the worldwide implementation of prevention and early detection strategies, including the Papanicolaou smear test, human papillomavirus (HPV) testing, and vaccines, approximately $30 \%$ of newly diagnosed cases still fall into the category of "locally advanced disease," indicating tumor spreading outside the uterine cervix (Féderation Internationale Gynécologie Obstétrique (FIGO) stages IIA-IVA) or bulky disease confined in the uterine cervix (FIGO stage IB2), at the time of diagnosis [3]. Moreover, $50 \%$ of patients with locally advanced disease are expected to relapse within the first 2 years after initial treatment [4].

Cisplatin monotherapy, often combined with externalbeam irradiation, remained the dominant treatment for locally advanced disease for more than fifteen years [5]. More recently, induction chemotherapy strategies followed by concurrent chemoradiation or surgery and preoperative concurrent chemoradiation have been implemented in the therapeutic armamentarium in an effort to optimize local control and at the same time to minimize the risk for metastatic disease. In this context, cisplatin has been combined with a number of 
other potential radiosensitizers to enhance cytotoxic activity. In parallel, numerous non-platinum-containing regimens have been developed for patients who either fail or become intolerant to platinum compounds. More recently, molecular agents targeting critical pathways in cervical malignant transformation are being assessed in early clinical trials in combination with external-beam irradiation, heralding the era of concurrent "bioradiotherapy" for locally advanced cervical cancer. In the current work, we review the evolving role of cisplatin and other platinum compounds, either alone or in combination regimens, in the context of other potent radiosensitizers. Moreover, we discuss the emerging role of molecular targeted agents as candidate partners of external beam irradiation in patients with locally advanced cervical cancer.

\section{Concurrent Chemoradiation Based on Platinum-Containing Regimens}

Radiation alone fails to control disease in over $35 \%$ of patients with cervical cancer diagnosed at FIGO stages IB2-IVA [6]. Five-year survival rates up to $72.2 \%, 63.7 \%, 41.7 \%$, and $16.4 \%$ for stages IB2, IIB, IIIB, and IVA, respectively, have been reported with exclusive radiation [7]. Concurrent chemoradiation has led to a significant benefit in reducing both local and distant recurrences in five randomized studies [8-12] that involved a total of 1,894 women. In the trial conducted by the Radiotherapy Oncology Group (RTOG), Morris et al. [12] randomized 401 stage IB-IVA patients to either concurrent chemoradiation with cisplatin and 5-fluorouracil (5FU) or to extended-field radiation alone (control group). Concurrent chemoradiotherapy resulted in a 5-year overall survival rate of $73 \%$ compared to $58 \%$ for radiation alone and decreased the rates for both local and distant recurrences. In another prospective phase III multicenter randomized trial reported at the same time with the former one, Rose et al. [11] recruited 526 evaluable patients with stage IIB-IVA cervical cancer in a Gynecologic Oncology Group (GOG) three-arm trial that compared weekly cisplatin versus cisplatin and 5-FU and hydroxyurea versus hydroxyurea alone, concurrently with radiation therapy. Superior survival rates for both cisplatin-containing regimens (66\% and 64\%, resp.) compared with hydroxyurea alone (39\%) were reported [11]. Moreover, cisplatin monotherapy was proven to be less toxic than the cisplatin/5-FU/hydroxyurea combination [11] or the protracted venous infusion (PVI) 5-FU [13]. Whitney et al. [10] randomized 388 patients with stage IIB-IVA disease in a Gynecologic Oncology Group (GOG) trial to receive either radiation therapy with concurrent cisplatin and 5-FU or hydroxyurea. Patients in the cisplatin arm had a significantly better 5-year survival rate (63\% versus $47 \%)$. In a metaanalysis based on 19 trials (including a total of 4,580 patients), an absolute survival benefit of $12 \%$ at 5 years with concurrent chemoradiation based on cisplatin as compared to radiation alone was demonstrated [14]. An update of the same work comprising 24 trials involving 4,921 patients showed that chemoradiation improves both overall survival (OS) and progression-free survival (PFS), when a platinum compound was used, with an absolute benefit of $10 \%$ [15]. Importantly, in a pilot study conducted by Nugent et al. [16], the number of cisplatin chemotherapy cycles was independently predictive for PFS and OS: patients who received less than six cycles had worse clinical outcome as compared to those who completed at least six cycles of treatment. Regarding the optimal dosing, a randomized trial comparing cisplatin at $40 \mathrm{mg} / \mathrm{m}^{2}$ weekly with cisplatin at $75 \mathrm{mg} / \mathrm{m}^{2}$ every 3 weeks reported twice as many delays of therapy with the higher, less frequent cisplatin administration [17]. On the ground of available evidence regarding clinical efficacy and acceptable tolerance, weekly cisplatin at the dose of $40 \mathrm{mg} / \mathrm{m}^{2}$ is considered the standard regimen that other agents should be compared to [18].

Although carboplatin may also serve as an active radiosensitizer [19-23] and is less toxic than cisplatin in patients with renal dysfunction due to ureteral obstruction, efficacy results from phase I-II trials (Table 2 ) are generally modest and objective response rates (ORR) are inferior to those reported with cisplatin [20-24]. Multiple combinations that incorporated carboplatin have been evaluated, with the combination of docetaxel with carboplatin exhibiting encouraging results $[21,22]$. The weekly paclitaxel and carboplatin chemoradiation regimen has been also proven feasible and active in phase I trials [23, 24], yet dose-limiting diarrhea makes this regimen poorly tolerated [25]. Concurrent chemoradiation with tegafur-uracil (UFT) and carboplatin showed no difference in respect to ORR, PFS, OS, and treatment-related toxicity as compared to carboplatin alone in a prospective, phase III trial that recruited 469 patients with stage IIB-IIIB cervical cancer [26]. Finally, in a case-control study [27], the combination of radiotherapy, concurrently with 5-FU and carboplatin, has been compared to radiation alone in the same setting: the authors reported similar ORR, DFS, and OS between the two groups of patients. Acute toxicity, primarily hematologic, was significantly higher in the cases than in the controls (25\% versus 3\%) [27].

Since 5-FU represents a potent radiosensitizer too, a number of studies have been undertaken to clarify the use of both agents in combination with pelvic radiotherapy. In a study by Kim et al. [28], 158 patients with FIGO stage IIB through IVA disease were assigned to either monthly 5-FU and cisplatin or weekly cisplatin concurrent with pelvic radiotherapy and high-dose rate brachytherapy. The response rate for each group was 91\%. Four-year OS and PFS rates were $70 \%$ and $67 \%$, respectively, with the combination regimen, while with weekly cisplatin they were $67 \%$ and $66 \%$, respectively. The authors concluded that chemoradiation with weekly cisplatin significantly improved compliance with treatment and reduced acute hematologic toxicity without affecting response and survival rates compared to the combination arm. Another trial designed to compare protracted venous infusion (PVI) of 5-FU with standard weekly cisplatin and concurrent RT in patients with stages IIB, IIIB, and IVA cervical cancer was prematurely terminated when a planned interim analysis indicated that the PVI 5-FU/RT treatment arm had a higher treatment failure rate (35\% higher) and would, most likely, not result in any improvement in PFS compared with weekly cisplatin/RT [13]. Yet clinical interest in 5-FU and its combinations is still active: recently, in a study 
TABLE 1: Randomized phase III clinical trials comparing platinum combinations to platinum monotherapy concurrently with external beam irradiation in patients with locally advanced cervical cancer.

\begin{tabular}{|c|c|c|c|c|c|c|}
\hline Trial & Year & $\begin{array}{l}\text { Experimental } \\
\text { regimen }\end{array}$ & $N$ & FIGO stage & Primary outcome & Remarks \\
\hline Morris et al. [12] & 1999 & $\begin{array}{l}\text { Cisplatin } \\
5 \text {-FU }\end{array}$ & 401 & IB-IVA & 5-year OS rate: $73 \%$ & $\begin{array}{l}\text { Concurrent CRT decreased the rates for both } \\
\text { local and distant recurrence }\end{array}$ \\
\hline Rose et al. [11] & 1999 & $\begin{array}{l}\text { Cisplatin } \\
5 \text {-FU } \\
\text { Hydroxyurea }\end{array}$ & 526 & IIB-IVA & 5-year OS rate: & $\begin{array}{l}\text { Combination more toxic than cisplatin } \\
\text { monotherapy }\end{array}$ \\
\hline Whitney et al. [10] & 1999 & $\begin{array}{l}\text { Cisplatin } \\
5 \text {-FU }\end{array}$ & 388 & IIB-IVA & 5 -year OS rate: $63 \%$ & Superior to hydroxyurea alone \\
\hline Veerasarn et al. [26] & 2007 & $\begin{array}{l}\text { Carboplatin } \\
\text { tegafur-uracil }\end{array}$ & 469 & IIB-IIIB & $\begin{array}{l}5 \text {-year PFS and OS were } \\
76 \% \text { and } 93 \% \text {, respectively }\end{array}$ & $\begin{array}{l}\text { ORR, PFS, and OS not different to carboplatin } \\
\text { alone }\end{array}$ \\
\hline Kim et al. [28] & 2008 & $\begin{array}{l}\text { Cisplatin } \\
5 \text {-FU }\end{array}$ & 158 & IIB-IVA & 5-year OS rate: $70 \%$ & $\begin{array}{l}\text { Cisplatin monotherapy equally efficient and } \\
\text { less toxic }\end{array}$ \\
\hline Lanciano et al. [13] & 2005 & $\begin{array}{l}\text { Cisplatin } \\
\text { 5-FU (PVI) }\end{array}$ & NR & IIB-IVA & $\begin{array}{l}\text { 1-year PFS and OS were } \\
76 \% \text { and } 93 \% \text {, respectively }\end{array}$ & $\begin{array}{l}\text { Prematurely terminated for futility compared } \\
\text { to cisplatin }\end{array}$ \\
\hline $\begin{array}{l}\text { Dueñas-González } \\
\text { et al. [33] }\end{array}$ & 2011 & $\begin{array}{l}\text { Cisplatin } \\
\text { gemcitabine }\end{array}$ & 515 & IIB-IVA & 3-year PFS rate: $74.4 \%$ & $\begin{array}{l}\text { Significant OS benefit compared to cisplatin } \\
\text { monotherapy } \\
\text { Combination group also received adjuvant } \\
\text { chemotherapy }\end{array}$ \\
\hline
\end{tabular}

FIGO: International Federation of Gynecologic Oncology; CRT: chemoradiotherapy; OS: overall survival; PFS: progression-free survival; ORR: objective response rate; 5-FU: 5-fluorouracil; PVI: protracted venous infusion; $N$ : number of patients.

that reevaluated the efficacy of concurrent chemoradiation using 5-FU and cisplatin in 57 patients with stage IIB-IVA and bulky IB2-IIA tumors, an ORR of $91.5 \%$ with a 5 -year OS and a 3 -year PFS rate of $69.4 \%$ and $74.9 \%$, respectively, was reported [29]. In the same context, another study [30] compared survival outcomes and toxicities between concurrent chemoradiotherapy with cisplatin plus 5-FU and cisplatin plus paclitaxel in 93 patients with locally advanced cervical carcinoma: no significant differences were found in 5-year PFS or OS between the two treatment groups. Nevertheless, the cisplatin plus paclitaxel arm was associated with increased leukopenia, neutropenia, and peripheral neuropathy but less gastrointestinal toxicity (nausea) compared to the cisplatin plus 5-FU arm [30].

Capecitabine, an oral prodrug of 5-FU, has been also evaluated in the same setting with promising results. In a phase I study of daily capecitabine combined with weekly cisplatin and radiotherapy, a PFS at 12 months of $69.2 \%$ and at 24 months of $49.2 \%$ with an OS rate of $57.7 \%$ at 24 months was reported [31]. Following these results, a phase II study [32] evaluated 60 patients with stage IIB-IIIB disease who received capecitabine during radiation, followed by six cycles of capecitabine monotherapy. The ORR was $88 \%$, while the 1 year PFS and OS rates were $86 \%$ and $95 \%$, respectively. At 23 months, $76 \%$ of patients were progression-free and complete response (CR) was maintained in $90 \%$ of the 48 patients who originally achieved a CR [32].

In a pilot phase II study designed to investigate the feasibility, efficacy, and safety of gemcitabine in combination with irradiation in 19 chemonaive patients with FIGO stage IIIB cervical cancer, a CR was observed among 17 (89.5\%) of them and after a median follow-up time of 19.9 months, all patients were alive with sixteen of them remaining relapsefree [47]. On these grounds, the gemcitabine-cisplatin combination was administered concurrently with radiotherapy in a phase I/II study resulting in a $97.3 \%$ ORR $(88.8 \%$ were complete responses). The 3-year RFS and OS rates were estimated to be $67 \%$ and $72 \%$, respectively [34]. These encouraging results led to a large randomized, phase III trial [33] (Table 1) designed to determine whether the addition of gemcitabine to concurrent cisplatin chemoradiotherapy could improve outcome compared with current standard of care in locally advanced cervical cancer: five hundred and fifteen patients with stage IIB-IVA disease were randomly assigned to either cisplatin and gemcitabine, weekly for 6 weeks with concurrent external-beam radiotherapy, followed by brachytherapy and then two adjuvant cycles of cisplatin plus gemcitabine, (arm A) or to cisplatin and concurrent radiotherapy followed by brachytherapy only at the same doses (arm B). PFS at 3 years was significantly improved in arm A versus arm B (74.4\% versus $65.0 \%$, resp.; $P=0.029)$ as were overall PFS (hazard ratio $(\mathrm{HR})=0.68 ; 95 \% \mathrm{CI}, 0.49$ to $0.95 ; P=0.0227)$ and $\mathrm{OS}(\mathrm{HR}=0.68 ; 95 \% \mathrm{CI}, 0.49$ to $0.95 ; P=0.0224)$. The authors concluded that gemcitabine plus cisplatin chemoradiotherapy followed by brachytherapy and adjuvant gemcitabine/cisplatin chemotherapy improved survival outcomes with increased but clinically manageable toxicity when compared with standard treatment [33]. Although these results challenge the current standard of cisplatin monotherapy, since patients in the experimental arm also received two cycles of adjuvant chemotherapy, it is not clear to what extent the survival benefit observed in the experimental arm is attributable to the addition of gemcitabine in the chemoradiation phase or to the addition of an adjuvant chemotherapy phase itself. 
TABLE 2: Main phase I-II clinical trials of various platinum combinations and non-platinum-containing regimens concurrently with external beam irradiation in patients with locally advanced cervical cancer.

\begin{tabular}{|c|c|c|c|c|c|c|c|}
\hline Trial & Year & Phase & $\begin{array}{l}\text { Experimental } \\
\text { regimen }\end{array}$ & $N$ & FIGO stage & Primary outcome & Remarks \\
\hline Rao et al. [24] & 2005 & I & $\begin{array}{l}\text { Carboplatin } \\
\text { Paclitaxel }\end{array}$ & 15 & IB2-IVA & Feasible & $\begin{array}{l}\text { 2-year PFS and OS were } 80 \% \text { and } \\
86 \% \text {, respectively }\end{array}$ \\
\hline Colombo et al. [27] & 1997 & II & $\begin{array}{l}\text { Carboplatin } \\
\text { 5-FU }\end{array}$ & 28 & IIA-IVA & 5 -year OS rate: $66 \%$ & $\begin{array}{l}\text { ORR, PFS, and OS not different to } \\
\text { carboplatin alone }\end{array}$ \\
\hline Choi et al. [29] & 2008 & II & $\begin{array}{l}\text { Cisplatin } \\
\text { 5-FU }\end{array}$ & 57 & IB2-IVA & 5-year OS rate: $70 \%$ & ORR: $91.5 \%$ \\
\hline Sol et al. [30] & 2009 & $\begin{array}{c}\text { II } \\
\text { (randomized) }\end{array}$ & $\begin{array}{l}\text { Cisplatin } \\
\text { Paclitaxel }\end{array}$ & 93 & IB-IVA & $\begin{array}{l}\text { 5-year PFS and OS } \\
\text { were } 79.1 \% \text { and } \\
80.9 \% \text {, respectively }\end{array}$ & $\begin{array}{l}\text { Equally efficient but more toxic } \\
\text { than cisplatin/5-FU }\end{array}$ \\
\hline Domingo et al. [32] & 2009 & II & Capecitabine & 60 & IIB-IIIB & ORR: $88 \%$ & $\begin{array}{l}\text { 1-year PFS and OS were } 86 \% \text { and } \\
95 \% \text {, respectively }\end{array}$ \\
\hline Zarbá et al. [34] & 2003 & I-II & Gemcitabine & 36 & IIB-IVA & 3 -year OS rate: $72 \%$ & $88.8 \%$ complete response rate \\
\hline Zhang et al. [35] & 2010 & II & $\begin{array}{l}\text { Paclitaxel } \\
\text { Nedaplatin }\end{array}$ & 34 & IIB-IIIB & 2-year OS: $93 \%$ & $88 \%$ complete response rate \\
\hline Geara et al. [36] & 2010 & II & Paclitaxel & 31 & IB2-IVA & 5-year OS rate: $43 \%$ & Inferior to weekly cisplatin \\
\hline Zanetta et al. [37] & 2000 & II & $\begin{array}{l}\text { Paclitaxel } \\
\text { Ifosfamide } \\
\text { Cisplatin }\end{array}$ & 38 & $\begin{array}{l}\text { Bulky locally } \\
\text { advanced }\end{array}$ & ORR: $84.2 \%$ & Manageable toxicity \\
\hline Roberts et al. [38] & 2000 & II & Mitomycin C & 160 & IB2-IVA & 4-year PFS: 71\% & Better than radiotherapy alone \\
\hline Nguyen et al. [39] & 1991 & II & $\begin{array}{l}\text { Mitomycin C } \\
\text { 5-FU }\end{array}$ & 38 & IB-IVA & $\begin{array}{l}\text { Median OS: } 87 \\
\text { months }\end{array}$ & $\begin{array}{l}\text { Significantly higher OS than 5-FU } \\
\text { alone }\end{array}$ \\
\hline Christie et al. [40] & 1995 & II & $\begin{array}{l}\text { Mitomycin C } \\
\text { 5-FU }\end{array}$ & 93 & IB-IVA & 73.2 & 4 -year survival: $87 \%$ \\
\hline Berclaz et al. [41] & 2002 & II & $\begin{array}{l}\text { Cisplatin } \\
\text { Mitomycin C } \\
\text { 5-FU }\end{array}$ & 22 & IIB-IVA & ORR: $82 \%$ & $\begin{array}{l}\text { All patients developed acute } \\
\text { haematological toxicity }\end{array}$ \\
\hline Rose et al. [42] & 2012 & I & $\begin{array}{l}\text { Cisplatin } \\
\text { Topotecan }\end{array}$ & 11 & IB-IVA & Feasible & Platinum dose reduced to $30 \mathrm{mg} / \mathrm{m}^{2}$ \\
\hline Fabbro et al. [43] & 2010 & I & $\begin{array}{l}\text { Cisplatin } \\
\text { Irinotecan }\end{array}$ & 15 & IB2-IVA & Feasible & 2-year survival: $81 \%$ \\
\hline
\end{tabular}

FIGO: International Federation of Gynecologic Oncology; CRT: chemoradiotherapy; OS: overall survival; PFS: progression-free survival; ORR: objective response rate; 5-FU: 5-fluorouracil; PVI: protracted venous infusion; $N$ : number of patients.

TABLE 3: Main clinical trials implementing molecular targeted agents concurrently with external beam irradiation in patients with locally advanced cervical cancer.

\begin{tabular}{|c|c|c|c|c|c|c|c|}
\hline Trial & Year & Phase & $\begin{array}{l}\text { Experimental } \\
\text { regimen }\end{array}$ & $N$ & FIGO stage & Primary outcome & Remarks \\
\hline Nogueira-Rodrigues et al. [44] & 2008 & I & Erlotinib & 15 & IIB-IIIB & Feasible & Recommended erlotinib dose: $150 \mathrm{mg}$ \\
\hline Moore et al. [45] & 2012 & I & Cetuximab & $>20$ & IIA-IVA & Feasible & $\begin{array}{l}\text { Not feasible in patients with extended } \\
\text { field radiation therapy }\end{array}$ \\
\hline Schefter et al. [46] & 2012 & I-II & $\begin{array}{l}\text { Bevacizumab } \\
\text { Cisplatin }\end{array}$ & 60 & IB-IIIB & Feasible & Hematologic toxicity common \\
\hline
\end{tabular}

FIGO: International Federation of Gynecologic Oncology.

Nedaplatin is a synthetic analog of cisplatin that exhibits less nephrotoxicity, neurotoxicity, and gastrointestinal toxicity. Weekly nedaplatin concurrently with radiation achieved an ORR of $90 \%$, a 3 -year PFS of $58.7 \%$, and an OS of $78.0 \%$ in a pilot phase II trial [48]. In a following randomized phase II study, nedaplatin-based concurrent chemoradiotherapy showed superior clinical efficacy and no statistically significant difference in toxicity as compared to radiotherapy alone [49]. Multiple combinations incorporating nedaplatin have also been evaluated, mainly in phase I trials. The combination of paclitaxel and nedaplatin concurrently with radiotherapy, followed by consolidation treatment with the same regimen, 
resulted in a CR of $88 \%$ and an estimated 2-year PFS and OS rate of $82 \%$ and $93 \%$, respectively [35].

\section{Concurrent Chemoradiation Based on Non-Platinum-Containing Regimens}

Among taxanes and other microtubule-targeting agents, paclitaxel has been extensively evaluated within chemoradiation regimens. The feasibility of concurrent radiotherapy and paclitaxel administration was evaluated in a pilot study with 20 patients ( 13 new cases, stage IIB-III, and 7 with pelvic recurrences) and complete regression was reported in $63 \%$ [50]. In a subsequent randomized phase II trial, weekly cisplatin was compared to weekly paclitaxel as concurrent chemotherapy with standard RT in patients with stage IB2IVA disease or with postsurgical pelvic recurrence: the proportion of patients surviving at 2 and 5 years was $78 \%$ and $54 \%$ for the cisplatin arm and $73 \%$ and $43 \%$ for the paclitaxel arm, respectively, thus suggesting that weekly paclitaxel does not provide any clinical advantage over weekly cisplatin [36]. A multiagent regimen that included paclitaxel, ifosfamide, and cisplatin (TIP) has been also evaluated in two different settings: bulky and locally advanced cervical cancer and recurrent-persistent disease in a total of 38 patients-eleven women achieved a clinical CR, 21 had a partial response, and only one patient had progressive disease (PD), accounting for an impressive ORR of $84.2 \%$ [37]. Finally, the combination of paclitaxel and vinorelbine was associated with significant hematologic toxicity [51].

Mitomycin $\mathrm{C}$ is an antineoplastic antibiotic drug that has been extensively evaluated in the locally advanced cervical cancer setting: in an earlier study, 40 patients with stage IBIVA disease received mitomycin $\mathrm{C}$ and 5-FU followed by sequential pelvic irradiation-a complete response rate of $63 \%$, a local control rate of $58 \%$, and a 5-year survival rate of $44 \%$ were obtained which were not superior to those achieved with radiation alone [52]. Another larger trial randomized 160 patients with locally advanced disease to receive either RT alone or RT with concomitant mitomycin C: the fouryear DFS rates for RT with mitomycin $\mathrm{C}$ and RT alone were significantly different (71\% versus $44 \%$ ) [38]. Using a combination regimen of 5-FU with mitomycin $\mathrm{C}$ and radiotherapy, Ludgate et al. suggested an improvement in pelvic control and in the 3-year survival rate for the combined modality compared to RT alone (55\% versus $28 \%$ ) using, however, historical controls with remarkably low response rates as a reference [53]. Similar results were obtained in another study using the same combination concurrently with $\mathrm{RT}$, although the authors commented that the regimen failed to control distant metastasis in late-stage patients [39]. In a pilot trial, 60 women with advanced cervical cancer were treated with a combination of external and intracavitary RT along with one cycle of 5-FU and mitomycin $\mathrm{C}$ and a second cycle of 5-FU and cisplatin. The 5-year OS for stage IIB and IIIA-IVA patients was $48 \%$ and $39 \%$, respectively [54]. Christie et al. reviewed 177 patients treated with pelvic radiotherapy for locally advanced disease and focused on
93 patients who had received chemotherapy with infusional 5-FU with or without bolus mitomycin C. The median OS for all patients was 47 months but was significantly higher (87 months) for the combination regimen group. Rates of PFS and local control were also higher in the same group, albeit at the cost of substantial toxicity, with $36 \%$ of patients in the combination arm experiencing grade 3 or 4 complications [40]. Finally, in a phase II trial [41], women with FIGO stage IIB-IVA disease who received cisplatin, 5-FU, mitomycin C, and concomitant radiotherapy achieved an ORR of $82 \%$. All patients developed acute hematological toxicity and two patients experienced severe late bowel toxicity. The lack of clinical efficacy improvement compared to historical controls treated with cisplatin alone and the late bowel toxicity discouraged further use of that regimen [41].

Topotecan and irinotecan are topoisomerase II inhibitors that have been evaluated in combination with RT in locally advanced cervical cancer. The feasibility of adding weekly topotecan to cisplatin in 12 patients with stage IB2-IVA disease receiving pelvic irradiation has been affirmed in a pilot trial and responses up to $92 \%$ were reported [55]. In a validation phase I cohort, intravenous topotecan at the dose of $0.5 \mathrm{mg} / \mathrm{m}^{2}$ and cisplatin at the dose of $30 \mathrm{mg} / \mathrm{m}^{2}$ given weekly for 6 weeks with concurrent pelvic radiation and intracavitary brachytherapy were tolerable [42]. The safety and feasibility of concurrent radiation therapy and weekly irinotecan in patients with locally advanced disease were also reported in two small phase II trials, showing promising efficacy and mostly tolerable adverse events $[43,56]$. However, further and larger studies will be required in order to clarify the exact role of camptothecins in combination with RT in the locally advanced setting of cervical cancer.

\section{Molecular Targeted Agents as Radiosensitizers}

The ongoing elucidation of the critical steps in the process of malignant transformation of the cervical epithelium has revealed important biological pathways, including neoangiogenesis and proliferate signal transduction, as appealing therapeutic targets for molecules targeting these aberrant pathways. Consequently, a number of biological agents are currently in clinical development (Table 3), aiming at inhibiting angiogenesis, targeting epidermal growth factor receptor (EGFR), cell cycle, histone deacetylases, cyclooxygenase2 (COX-2), or mammalian target of rapamycin (mTOR) [57]. In locally advanced disease, in particular, the potential synergy between the cytotoxic effect of irradiation and the proapoptotic effect of molecular agents targeting pathways crucial for cancer cell survival has generated the hypothesis that administration of these agents concurrently with radiotherapy may enhance clinical benefit while reducing chemotherapy-associated toxicity [58]. EGFR-targeting agents were the first molecules to be tested as radiotherapy partners in this setting, with the EGFR tyrosine kinase inhibitor erlotinib demonstrating feasibility and safety in concomitant administration with radiotherapy at the dose of 
$150 \mathrm{mg}$ daily in a pilot phase I trial [44]. The chimeric monoclonal antibody against EGFR cetuximab was also tested in combination with radiotherapy in patients with newly diagnosed locally advanced cervical cancer in a recently reported phase I trial showing that the combination was feasible for patients receiving pelvic radiotherapy but not feasible for patients receiving extended field radion therapy due to nodal metastases [45]. Based on this preliminary evidence, a phase II pilot trial incorporating cetuximab, cisplatin, and irradiation in women with locally advanced cervical cancer is currently ongoing (ClinicalTrials.gov Identifier: NCT00292955).

Angiogenesis is central to cervical cancer development and progression, as it seems to be directly related to HPV inhibition of p53 and subsequent stabilization of hypoxiainducible factor-one alpha (HIF-1 alpha), both of which increase the levels of vascular endothelial growth factor (VEGF) [59]. Bevacizumab, a monoclonal antibody against VEGF, was recently tested in combination with radiotherapy and cisplatin chemotherapy in a phase II study [46] involving 49 evaluable, previously untreated patients with locally advanced cervical cancer. The study demonstrated the feasibility of the combination, as $76 \%$ of the patients received bevacizumab and cisplatin according to the study protocol and $94 \%$ of them had both external beam irradiation and brachytherapy administered as per protocol or with acceptable variation [46]. On these grounds, a phase II study of bevacizumab in combination with definitive radiotherapy and cisplatin chemotherapy in the same setting has completed accrual and results are awaited (ClinicalTrials.gov Identifier: NCT00369122). Several VEGF receptor tyrosine kinase inhibitors (VEGFR-TKI), such as sunitinib and pazopanib, are being currently tested in phase II studies in recurrent or metastatic disease (ClinicalTrials.gov Identifier: NCT00389974) but their development in the locally advanced setting is hampered by safety concerns regarding increased rates of fistula formation, especially when combined with external beam irradiation.

\section{Conclusions}

During the past three decades, efforts to enhance cytotoxic activity of radiotherapy using radiosensitizers have evolved from single agent cisplatin administration to sophisticated regimens incorporating various platinum and non-platinumcontaining regimens. Most of these regimens led to moderate improvements in response rates and progression-free survival, however, at the cost of moderate to substantial toxicity. Nevertheless, with the sole exception of the cisplatingemcitabine combination [33], none of the regimens has thus far been associated with improved survival outcomes. The advent of the bioradiotherapy era is anticipated to lead to the identification of more "sophisticated" therapeutic combinations exploiting the potential synergy between irradiation and molecular inhibition of critical signaling pathways and to enable the design of robust clinical trials based on strong biological rational.

\section{References}

[1] F. Kamangar, G. M. Dores, and W. F. Anderson, "Patterns of cancer incidence, mortality, and prevalence across five continents: defining priorities to reduce cancer disparities in different geographic regions of the world," Journal of Clinical Oncology, vol. 24, no. 14, pp. 2137-2150, 2006.

[2] C. Mathers, T. Boerma, and D. Ma Fat, "The global burden of disease: 2004 update," World Health Organization, Geneva, Switzerland, 2008, http://www.who.int/healthinfo/global_burden_disease/GBD_report_2004update_full.pdf.

[3] L. A. G. Ries, D. Harkins, M. Krapcho et al., SEER Cancer Statistics Review, 1975-2003, National Cancer Institute, Bethesda, Md, USA, 2006.

[4] P. J. Eifel, "Concurrent chemotherapy and radiation therapy as the standard of care for cervical cancer," Nature Reviews Clinical Oncology, vol. 3, no. 5, pp. 248-255, 2006.

[5] S. Movva, L. Rodriguez, H. Arias-Pulido, and C. Verschraegen, "Novel chemotherapy approaches for cervical cancer," Cancer, vol. 115, no. 14, pp. 3166-3180, 2009.

[6] Z. Al-Mansour and C. Verschraegen, "Locally advanced cervical cancer: what is the standard of care?" Current Opinion in Oncology, vol. 22, pp. 503-512, 2010.

[7] "Annual report on the results of treatment in gynaecological cancer," Journal of Epidemiology Statistics, vol. 3, pp. 5-34, 1998.

[8] W. A. Peters III, P. Y. Liu, R. J. Barrett et al., "Concurrent chemotherapy and pelvic radiation therapy compared with pelvic radiation therapy alone as adjuvant therapy after radical surgery in high-risk early-stage cancer of the cervix," Journal of Clinical Oncology, vol. 18, no. 8, pp. 1606-1613, 2000.

[9] V. Lorvidhaya, I. Chitapanarux, S. Sangruchi et al., "Concurrent mitomycin C, 5-fluorouracil, and radiotherapy in the treatment of locally advanced carcinoma of the cervix: a randomized trial," International Journal of Radiation Oncology Biology Physics, vol. 55, no. 5, pp. 1226-1232, 2003.

[10] C. W. Whitney, W. Sause, B. N. Bundy et al., "Randomized comparison of fluorouracil plus cisplatin versus hydroxyurea as an adjunct to radiation therapy in stage IIB-IVA carcinoma of the cervix with negative para-aortic lymph nodes. A Gynecologic Oncology Group and Southwest Oncology Group Study," Journal of Clinical Oncology, vol. 17, no. 5, pp. 1339-1348, 1999.

[11] P. G. Rose, B. N. Bundy, E. B. Watkins et al., "Concurrent cisplatin-based chemoradiation improves progression free and overall survival in advanced cervical cancer. Results of a randomized Gynecologic Oncology Group Study," New England Journal of Medicine, vol. 340, pp. 1144-1153, 1999.

[12] M. Morris, P. J. Eifel, J. Lu et al., "Pelvic radiation with concurrent chemotherapy compared with pelvic and paraaortic radiation for high-risk cervical cancer," New England Journal of Medicine, vol. 340, no. 15, pp. 1137-1143, 1999.

[13] R. Lanciano, A. Calkins, B. N. Bundy et al., "Randomized comparison of weekly cisplatin or protracted venous infusion of fluorouracil in combination with pelvic radiation in advanced cervix cancer. A Gynecologic Oncology Group study," Journal of Clinical Oncology, vol. 23, no. 33, pp. 8289-8295, 2005.

[14] J. A. Green, J. M. Kirwan, J. F. Tierney et al., "Survival and recurrence after concomitant chemotherapy and radiotherapy for cancer of the uterine cervix: a systematic review and metaanalysis," Lancet, vol. 358, no. 9284, pp. 781-786, 2001.

[15] J. Green, J. Kirwan, J. Tierney et al., "Concomitant chemotherapy and radiation therapy for cancer of the uterine cervix," 
Cochrane Database of Systematic Reviews, no. 3, Article ID CD002225, 2005.

[16] E. K. Nugent, A. S. Case, J. T. Hoff et al., "Chemoradiation in locally advanced cervical carcinoma: an analysis of cisplatin dosing and other clinical prognostic factors," Gynecologic Oncology, vol. 116, pp. 438-441, 2010.

[17] B. Chumworathayi, P. Suprasert, K. Charoenkwan et al., "Weekly versus three-weekly cisplatin as an adjunct to radiation therapy in high-risk stage I-IIA cervical cancer after surgery: a randomized comparison of treatment compliance," Journal of the Medical Association of Thailand, vol. 88, no. 11, pp. 14831492, 2005.

[18] P. G. Rose, "Concurrent chemoradiation for locally advanced carcinoma of the cervix: where are we in 2006?" Annals of Oncology, vol. 17, no. 10, supplement, pp. x224-x229, 2006.

[19] E. Micheletti, B. La Face, E. Bianchi et al., "Continuous infusion of carboplatin during conventional radiotherapy treatment in advanced squamous carcinoma of the cervix uteri IIB-IIIB (UICC): a phase I/II and pharmacokinetic study," American Journal of Clinical Oncology, vol. 20, no. 6, pp. 613-620, 1997.

[20] L. Cetina, A. Garcia-Arias, M. de Jesus Uribe et al., "Concurrent chemoradiation with carboplatin for elderly, diabetic and hypertensive patients with locally advanced cervical cancer," European Journal of Gynaecological Oncology, vol. 29, no. 6, pp. 608-612, 2008.

[21] D. T. Rein, C. M. Kurbacher, M. Breidenbach et al., "Weekly carboplatin and docetaxel for locally advanced primary and recurrent cervical cancer: a phase I study," Gynecologic Oncology, vol. 87, no. 1, pp. 98-103, 2002.

[22] S. Takekida, K. Fujiwara, S. Nagao et al., "Phase II study of combination chemotherapy with docetaxel and carboplatin for locally advanced or recurrent cervical cancer.," International Journal of Gynecological Cancer, vol. 20, no. 9, pp. 1563-1568, 2010.

[23] D. Addeo, S. Blank, F. Muggia, and S. Formenti, "Concurrent radiotherapy, paclitaxel and dose escalating carboplatin in the treatment of cervical cancer-a phase I study," Anticancer Research, vol. 28, no. 5, pp. 3143-3146, 2008.

[24] G. G. Rao, P. Rogers, R. D. Drake, P. Nguyen, and R. L. Coleman, "Phase I clinical trial of weekly paclitaxel, weekly carboplatin, and concurrent radiotherapy for primary cervical cancer," Gynecologic Oncology, vol. 96, no. 1, pp. 168-172, 2005.

[25] F. Y. F. L. De Vos, A. M. E. Bos, J. A. Gietema et al., "Paclitaxel and carboplatin concurrent with radiotherapy for primary cervical cancer," Anticancer Research, vol. 24, no. 1, pp. 345-348, 2004.

[26] V. Veerasarn, V. Lorvidhaya, P. Kamnerdsupaphon et al., "A randomized phase III trial of concurrent chemoradiotherapy in locally advanced cervical cancer: preliminary results," Gynecologic Oncology, vol. 104, no. 1, pp. 15-23, 2007.

[27] A. Colombo, F. Landoni, G. Cormio et al., "Concurrent carboplatin/5FU and radiotherapy compared to radiotherapy alone in locally advanced cervical carcinoma: a case-control study," Tumori, vol. 83, no. 6, pp. 895-899, 1997.

[28] Y. S. Kim, S. S. Shin, J. H. Nam et al., "Prospective randomized comparison of monthly fluorouracil and cisplatin versus weekly cisplatin concurrent with pelvic radiotherapy and highdose rate brachytherapy for locally advanced cervical cancer," Gynecologic Oncology, vol. 108, no. 1, pp. 195-200, 2008.

[29] I. J. Choi, M. S. Cha, E. S. Park et al., "The efficacy of concurrent cisplatin and 5-flurouracil chemotherapy and radiation therapy for locally advanced cancer of the uterine cervix," Journal of Gynecologic Oncology, vol. 19, no. 2, pp. 129-134, 2008.

[30] E. S. Sol, T. S. Lee, S. B. Koh, H. K. Oh, G. W. Ye, and Y. S. Choi, "Comparison of concurrent chemoradiotherapy with cisplatin plus 5-fluorouracil versus cisplatin plus paclitaxel in patients with locally advanced cervical carcinoma," Journal of Gynecologic Oncology, vol. 20, no. 1, pp. 28-34, 2009.

[31] Z. Stokes, P. Symonds, T. Habeshaw et al., "Phase one dose finding study of capecitabine (Xeloda $®$ ), radiotherapy and cisplatin in the treatment of locally advanced squamous cervical cancer," Gynecologic Oncology, vol. 97, no. 3, pp. 790-795, 2005.

[32] E. Domingo, V. Lorvidhaya, R. De Los et al., "Capecitabinebased chemoradiotherapy with adjuvant capecitabine for locally advanced squamous carcinoma of the uterine cervix: phase II results," Oncologist, vol. 14, no. 8, pp. 828-834, 2009.

[33] A. Dueñas-González, J. J. Zarbá, F. Patel et al., "Phase III, openlabel, randomized study comparing concurrent gemcitabine plus cisplatin and radiation followed by adjuvant gemcitabine and cisplatin versus concurrent cisplatin and radiation in patients with stage IIB to IVA carcinoma of the cervix," Journal of Clinical Oncology, vol. 29, no. 13, pp. 1678-1685, 2011.

[34] J. J. Zarbá, A. V. Jaremtchuk, P. Gonzalez Jazey et al., "A phase I-II study of weekly cisplatin and gemcitabine with concurrent radiotherapy in locally advanced cervical carcinoma," Annals of Oncology, vol. 14, no. 8, pp. 1285-1290, 2003.

[35] M. Q. Zhang, S. P. Liu, and X. E. Wang, "Concurrent chemoradiotherapy with paclitaxel and nedaplatin followed by consolidation chemotherapy in locally advanced squamous cell carcinoma of the uterine cervix: preliminary results of a phase II study," International Journal of Radiation Oncology Biology Physics, vol. 78, no. 3, pp. 821-827, 2010.

[36] F. B. Geara, A. Shamseddine, A. Khalil, M. Abboud, M. Charafeddine, and M. Seoud, "A phase II randomized trial comparing radiotherapy with concurrent weekly cisplatin or weekly paclitaxel in patients with advanced cervical cancer," Radiation Oncology, vol. 5, no. 1, article 84, 2010.

[37] G. Zanetta, F. Fei, and C. Mangioni, "Chemotherapy with paclitaxel, ifosfamide, and cisplatin for the treatment of squamous cell cervical cancer: the experience of Monza," Seminars in Oncology, vol. 27, no. 1, supplement, pp. 23-27, 2000.

[38] K. B. Roberts, N. Urdaneta, and R. Vera, "Interim results of a randomized trial of mitomycin $\mathrm{C}$ as an adjunct to radical radiotherapy in the treatment of locally advanced squamous-cell carcinoma of the cervix," International Journal of Cancer, vol. 90, no. 4, pp. 206-223, 2000.

[39] P. D. Nguyen, B. John, A. K. Munoz, R. Yazigi, M. Graham, and P. Franklin, "Mitomycin-C/5-FU and radiation therapy for locally advanced uterine cervical cancer," Gynecologic Oncology, vol. 43, no. 3, pp. 220-225, 1991.

[40] D. R. Christie, C. A. Bull, V. Gebski, and A. O. Langlands, "Concurrent 5-fluorouracil, mitomycin $\mathrm{C}$ and irradiation in locally advanced cervix cancer," Radiotherapy and Oncology, vol. 37, no. 3, pp. 181-189, 1995.

[41] G. Berclaz, E. Gerber, K. Beer et al., "Long-term follow-up of concurrent radiotherapy and chemotherapy for locally advanced cervical cancer: 12-year survival after radiochemotherapy.," International Journal of Oncology, vol. 20, no. 6, pp. 1313-1318, 2002.

[42] P. G. Rose, M. W. Sill, S. McMeekin et al., "A phase I study of concurrent weekly topotecan and cisplatin chemotherapy with 
whole pelvic radiation therapy in locally advanced cervical cancer: a gynecologic oncology group study," Gynecologic Oncology, vol. 125, pp. 158-162, 2012.

[43] M. Fabbro, L. Gladieff, F. Guichard et al., "Phase I study of irinotecan and cisplatin in combination with pelvic radiotherapy in the treatment of locally advanced cervical cancer: a GINECO trial," Gynecologic Oncology, vol. 117, no. 2, pp. 276280, 2010.

[44] A. Nogueira-Rodrigues, C. C. Do Carmo, C. Viegas et al., "Phase I trial of erlotinib combined with cisplatin and radiotherapy for patients with locally advanced cervical squamous cell cancer," Clinical Cancer Research, vol. 14, no. 19, pp. 6324-6329, 2008.

[45] K. N. Moore, M. W. Sill, D. S. Miller et al., "A phase I trial of tailored radiation therapy with concomitant cetuximab and cisplatin in the treatment of patients with cervical cancer: a gynecologic oncology group study," Gynecologic Oncology, vol. 127, no. 3, pp. 456-461, 2012.

[46] T. E. Schefter, K. Winter, J. S. Kwon et al., "A phase II study of bevacizumab in combination with definitive radiotherapy and cisplatin chemotherapy in untreated patients with locally advanced cervical carcinoma: preliminary results of RTOG 0417," International Journal of Radiation Oncology.Biology.Physics, vol. 83, no. 4, pp. 1179-1184, 2012.

[47] P. Pattaranutaporn, C. Thirapakawong, Y. Chansilpa, S. Therasakvichya, N. Ieumwananontachai, and K. Thephamongkhol, "Phase II study of concurrent gemcitabine and radiotherapy in locally advanced stage IIIB cervical carcinoma," Gynecologic Oncology, vol. 81, no. 3, pp. 404-407, 2001.

[48] Y. Yokoyama, T. Takano, K. Nakahara et al., "A phase II multicenter trial of concurrent chemoradiotherapy with weekly nedaplatin in advanced uterine cervical carcinoma: Tohoku gynecologic cancer unit study," Oncology Reports, vol. 19, no. 6, pp. 1551-1556, 2008.

[49] S. Mabuchi, H. Ugaki, F. Isohashi et al., "Concurrent weekly nedaplatin, external beam radiotherapy and high-dose-rate brachytherapy in patients with FIGO stage IIIb cervical cancer: a comparison with a cohort treated by radiotherapy alone," Gynecologic and Obstetric Investigation, vol. 69, no. 4, pp. 224232, 2010.

[50] A. Cerrotta, G. Gardani, R. Cavina et al., "Concurrent radiotherapy and weekly paclitaxel for locally advanced or recurrent squamous cell carcinoma of the uterine cervix. A pilot study with intensification of dose," European Journal of Gynaecological Oncology, vol. 23, no. 2, pp. 115-119, 2002.

[51] A. J. Mundt, J. Rotmensch, S. E. Waggoner, D. Yamada, S. C. Langhauser, and G. F. Fleming, "Phase I trial of concomitant vinorelbine, paclitaxel, and pelvic irradiation in cervical carcinoma and other advanced pelvic malignancies," Gynecologic Oncology, vol. 82, no. 2, pp. 333-337, 2001.

[52] T. R. Denehy, R. Eastman, L. Sanfilippo, C. A. Gregori, and J. L. Breen, "Bolus mitomycin C and 5-FU with sequential radiation for poor-prognosis locally advanced cervical cancer," Gynecologic Oncology, vol. 60, no. 1, pp. 64-71, 1996.

[53] S. M. Ludgate, A. J. Crandon, C. N. Hudson, Q. Walker, and A. O. Langlands, "Synchronous 5-fluorouracil, mitomycin-C and radiation therapy in the treatment of locally advanced carcinoma of the cervix," International Journal of Radiation Oncology Biology Physics, vol. 15, no. 4, pp. 893-899, 1988.

[54] M. John, M. Flam, R. Caplan et al., "Final results of a phase II chemoradiation protocol for locally advanced cervical cancer:
RTOG 85-15," Gynecologic Oncology, vol. 61, no. 2, pp. 221-226, 1996.

[55] T. A. Gatcliffe, K. S. Tewari, A. Shah et al., "A feasibility study of topotecan with standard-dose cisplatin and concurrent primary radiation therapy in locally advanced cervical cancer," Gynecologic Oncology, vol. 112, no. 1, pp. 85-89, 2009.

[56] N. Suntornpong, Y. Chansilp, P. Pattaranutaporn, and K. Thephamongkhol, "Concurrent radiation therapy and irinotecan in stage IIIB cervical cancer," Journal of the Medical Association of Thailand, vol. 86, no. 5, pp. 430-435, 2003.

[57] F. Zagouri, T. N. Sergentanis, D. Chrysikos, M. Filipits, and R. Bartsch, "Molecularly targeted therapies in cervical cancer. A systematic review," Gynecologic Oncology, vol. 126, no. 2, pp. 291-303, 2012.

[58] L. González-Cortijo, N. Carballo, A. González-Martín et al., "Novel chemotherapy approaches in chemoradiation protocols," Gynecologic Oncology, vol. 110, no. 3, supplement 2, pp. S45-S48, 2008.

[59] B. J. Monk, L. J. Willmott, and D. A. Sumner, "Anti-angiogenesis agents in metastatic or recurrent cervical cancer," Gynecologic Oncology, vol. 116, no. 2, pp. 181-186, 2010. 


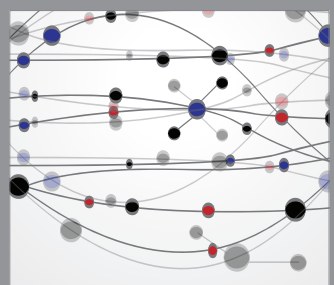

The Scientific World Journal
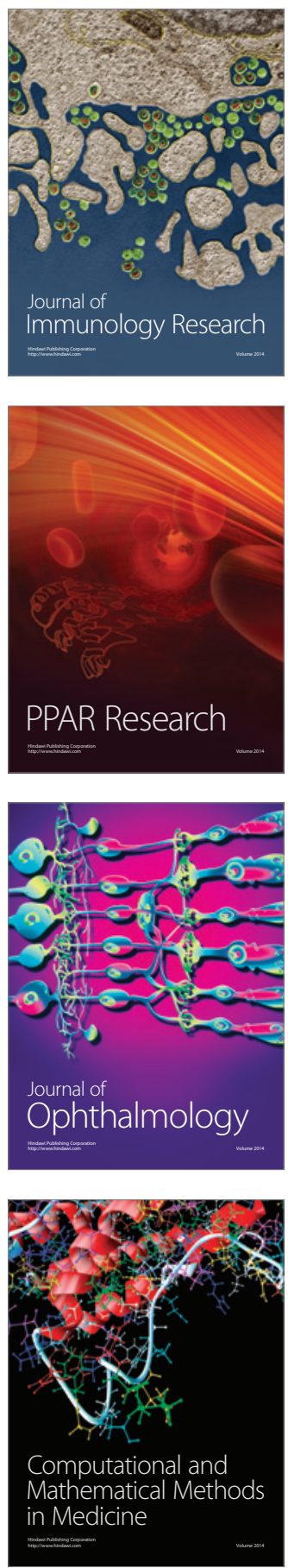

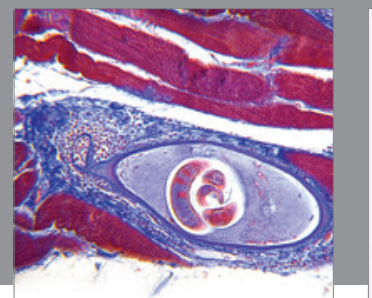

Gastroenterology

Research and Practice
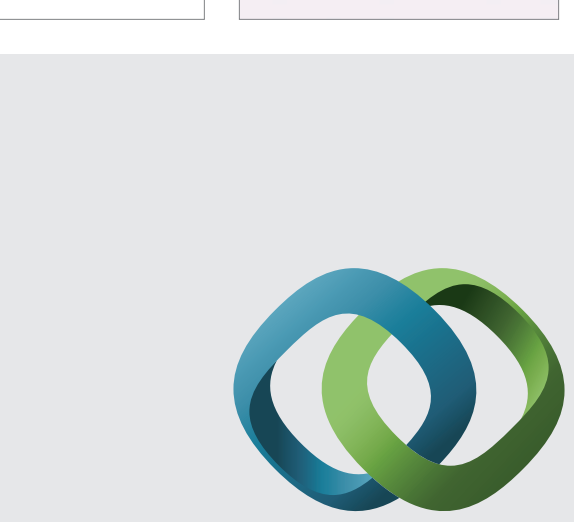

\section{Hindawi}

Submit your manuscripts at

http://www.hindawi.com
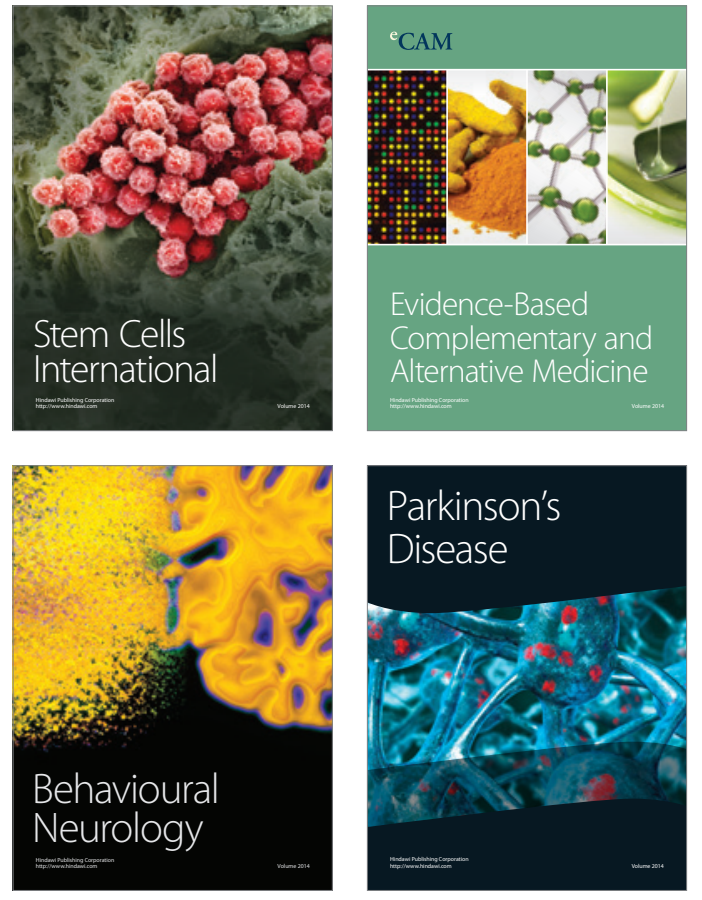
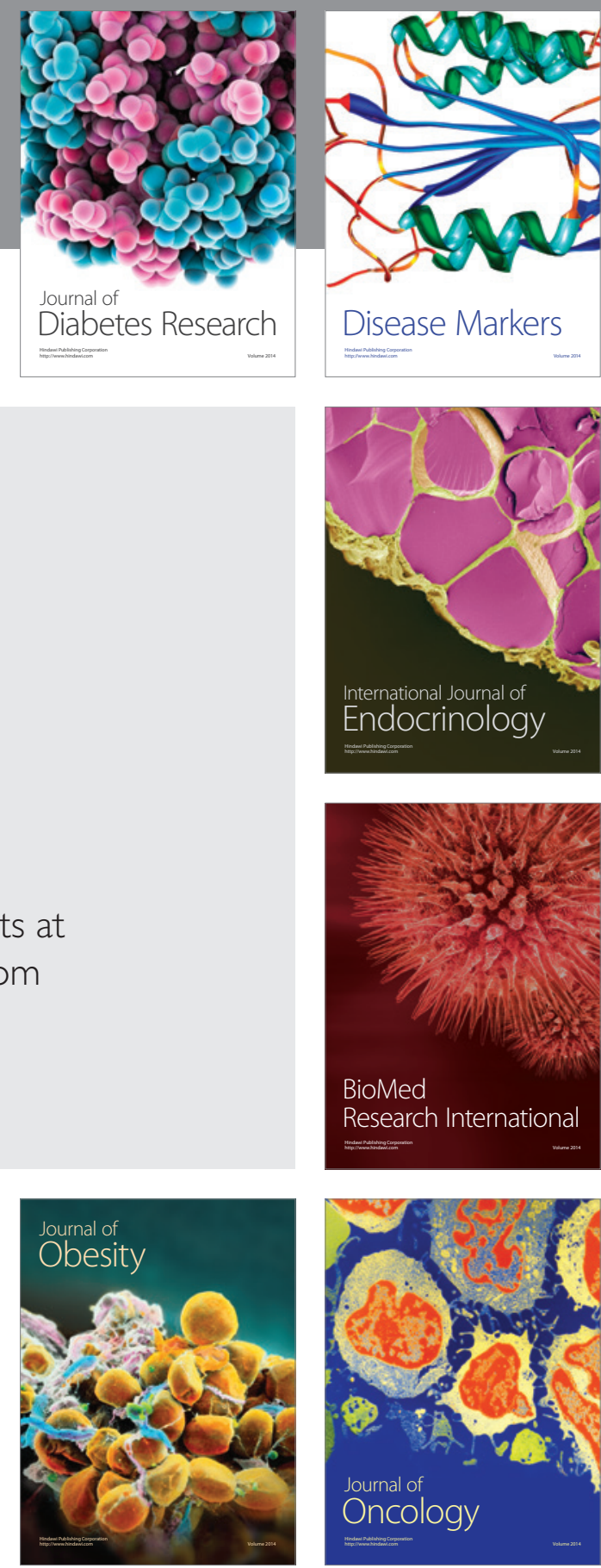

Disease Markers
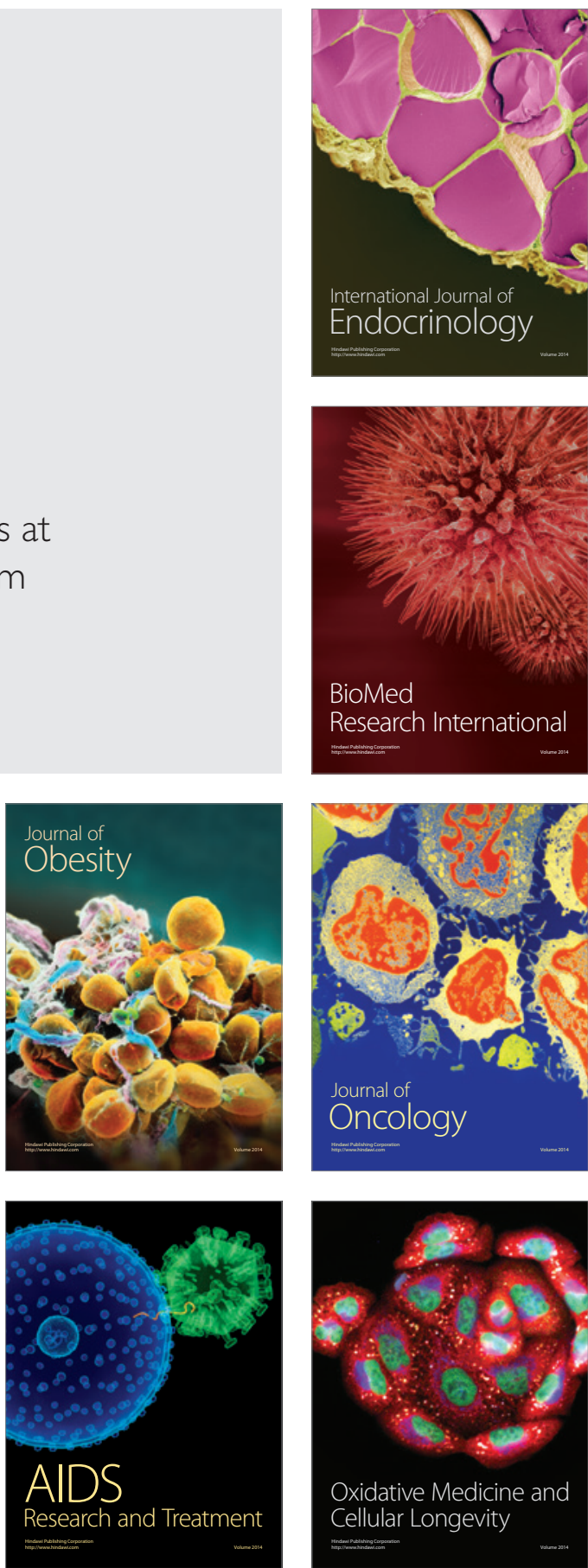